\title{
Benign Meningioma
}

National Cancer Institute

\section{Source}

National Cancer Institute. Benign Meningioma. NCI Thesaurus. Code C4055.

A grade I, slowly growing mening ioma. Only a minority of tumors recur following complete resection. 